\title{
“Ante un destino cierto": la escritura en la obra de Leonardo Sciascia como forma absoluta de verdad
}

\author{
Javier Serrano-Puche*
}

\begin{abstract}
Resumen: El universo poético de Leonardo Sciascia se asienta sobre la convicción de que la literatura es el ámbito donde la verdad acontece. Aunque está íntimamente asociada al deleite, la escritura literaria no es para el autor siciliano una recreación erudita en el propio saber ni un refugio cerrado a la comprensión de la realidad. Por el contrario, Sciascia intenta hallar un sentido a dicha realidad a través de las coincidencias y correspondencias que se establecen entre los hechos bajo la luz de su personal bagaje literario.
\end{abstract}

Palabras clave: Escritura, verdad, Leonardo Sciascia, intertextualidad, hermenéutica.

Abstract: Leonardo Sciascia's poetic universe is founded on the conviction that literature is the realm where truth happens. Although intimately associated with delight, literary writing is not -in the Sicilian's writer view- an erudite recreation of his own knowledge, nor a closed refuge from a comprehensive look at reality. On the contrary, Sciascia tries to find a meaning in that reality by analyzing the coincidences and connections among facts and events, in light of his personal literary background.

Key words: Writing, truth, Leonardo Sciascia, intertextuality, hermeneutics

Résumé: L'univers poétique de Leonardo Sciascia repose sur la conviction du fait que la littérature est le domaine où la vérité se fait jour. Bien que l'écriture littéraire soit intimement liée au délice, elle ne représente pas pour cet auteur sicilien une nouvelle création érudite au cœur de son propre savoir ni un refuge fermé à la compréhension de la réalité. Bien au contraire, Sciascia essaie de trouver un sens à cette réalité en analysant les coïncidences et les correspondances qui surgissent entre les faits, à la lumière de ses connaissances littéraires personnelles.

Mots-clés: Écriture, vérité, Leonardo Sciascia, intertextualité, herméneutique.

* Profesor Ayudante. Departamento de Comunicación Pública. Facultad de Comunicación. Universidad de Navarra, España. (jserrano@unav.es).

Recibido: 2010 - 02 - 01

Aprobado: 2010 - 05 - 17 
El 20 de noviembre de 1989, a la edad de 68 años y después de una larga y dolorosa enfermedad, el escritor siciliano Leonardo Sciascia falleció en su domicilio de Palermo ${ }^{1}$. Recientemente cumplido, pues, el vigésimo aniversario de su muerte, el legado literario de Sciascia sigue mostrándose como una obra compleja y extensa, reflejo de una no menos rica personalidad y evolución intelectual. Poeta, narrador, dramaturgo, columnista, investigador de hechos históricos, polemista, comprometido activamente en la vida política, consultor editorial, coleccionista de arte... Son diferentes facetas que se ensamblan de manera singular pero coherente en su universo poético, articulado en torno a una noción central que permite aunar esas vertientes tan dispares: la convicción de que la literatura, como expresaba en una anotación de su diario Nero su nero (1979), "es la forma más absoluta que puede asumir la verdad" ${ }^{2}$.

En las siguientes páginas intentaremos aproximarnos a dicha consideración sciasciana acerca de la dimensión veritativa de la escritura literaria. Veremos que desde la perspectiva del autor siciliano la literatura está relacionada, por un lado, con el deleite, con un sentido íntimo y vivencial de la literatura, invocada por medio de la memoria, realizada a través de la citación intertextual y entendida como una forma de felicidad que es transmisible al lector. Por otro lado, también tiene una función cognoscitiva

1 Sciascia había visitado médicos de Palermo, Roma, Milán, París y Suiza, que atribuían su delicado estado de salud a las secuelas de la fractura de vértebra sufrida por el escritor en una caída en 1980 y a su condición de fumador empedernido, pero no conseguían enunciar un diagnóstico claro. Los diversos medicamentos y terapias a los que se sometía el escritor apenas mitigaban su dolor. No será hasta abril de 1989 cuando, tras numerosos análisis en la clínica Città di Milano, finalmente le diagnostiquen un mieloma micromolecular, un raro tumor en la médula ósea que en la jerga médica llaman enfermedad de las "cadenas ligeras" y que causará la muerte del escritor. Cfr. M. Collura, Sciascia. El maestro de Regalpetra, traducción de M. J. Palomera, Madrid, Alfaguara, 2001, p. 355.

2 L. Sciascia, Negro sobre negro, traducción de C. Palma, Barcelona, Global Rhythm Press, 2007, p. 304. y desmistificante, porque con las operaciones de lectura, escritura y reescritura intenta comprender e iluminar una realidad que, cuando está relacionada con el poder, se encuentra envuelta en el misterio y la mentira. Esta tensión hermenéutica se encarna en la adopción de un discurso policiaco que presenta desviaciones respecto de la tradición del género, según el propósito de Sciascia de convertir la "escrituraengaño" en una "escritura-verdad".

\section{La memoria diletante, principio de la citación intertextual}

Como ha señalado Ricciarda Ricorda, en las obras de Sciascia hay personajes que ascienden al plano de la meditación, mientras que otros son rigurosamente excluidos, precisamente porque en el juego de las citaciones "algunos personajes adquieren su consistencia y se cualifican como portadores de un discurso esencial para determinar la posición ideológica del propio Sciascia" ${ }^{\prime 3}$. Pero ya sea atribuida a un determinado personaje, ya corresponda a la instancia narrativa, es la memoria el principio que desencadena la citación intertextual. La rememoración de fragmentos, personajes, versos o motivos literarios se erige como la perspectiva idónea para enjuiciar el mundo circundante y, paralelamente, como un intento de sustraerse al principio de realidad que conduce al hombre hacia su muerte.

Más aún, en el universo poético sciasciano la literatura está íntimamente asociada a la felici$\mathrm{dad}^{4}$, de la misma manera que la memoria lo está

3 R. Ricorda, Pagine vissute. Studi di letteratura italiana del Novecento, Napoli, Esi, 1995, p. 155.

4 De ahí que el Vice, el policía protagonista de Il cavaliere e la morte, piense: "La isla del tesoro: una lectura, como había dicho alguien, que era lo más parecido a la felicidad que cabía encontrar", en L. Sciascia, El caballero y la muerte, traducción de R. Pochtar, Barcelona, Tusquets, 1989, p. 81. 
al amor, según una noción que Sciascia aprendió del escritor Alberto Savinio, quien en su Nuova Enciclopedia afirmaba esa misma identificación:

Nosotros, los italianos, decimos conoscere a memoria, y también conoscere a mente [saber de memoria]. Los franceses dicen: connaître par coeur, los ingleses: To have by heart. ¿Qué se puede deducir de esto?, ¿que el italiano es más 'mental' que el francés y el inglés? Gusta, en cualquier caso, la forma francesa: la cosa que sabemos de memoria, sin necesidad de instrumentos o documentos intermedios, la sabemos 'por medio del corazón', o sea, la amamos, como si el recordar fuese amar, lo que, de hecho, es ${ }^{5}$.

En este sentido, parece pertinente recordar algunas consideraciones que Sciascia realizaba en el ensayo "Savinio", incluido en el volumen Cruciverba (1983), pues pueden proyectarse sobre su propia obra varios de los elementos estilísticos y poéticos que él elogiaba de aquel autor italiano de entreguerras. También el universo poético sciasciano, como el saviniano, es un mundo "de memoria, de incidencias, de coincidencias, de refracciones, de correspondencias" ${ }^{6}$. Como apuntábamos antes, en sus obras la lógica del relato se construye sobre la capacidad de establecer enlaces, transiciones, secuencias entre elementos diversos y gracias a la inclusión de otras voces literarias que surgen en la memoria del narrador o de un personaje que es portavoz del pensamiento del escritor siciliano. Y esto se produce desde una disposición anímica caracterizada por "el rechazo del hastío, el gusto, el deleitarse de la vida, el ser dilettanti"7 y que remite, en último término, a la actitud preeminente de su admirado Stendhal. Ese deleite lleva aparejada una voluntad estilística de claridad y ligereza, de una superficialidad bien entendida, de nuevo al modo de Alberto Savinio:

El concepto de transparencia sirve para comprender el continuo elogio que Savinio hace de la superficialidad, su amor por la superficialidad y

5 A. Savinio, Nueva enciclopedia, Barcelona, traducción de J. Pardo, Seix Barral, 1983, p. 292, s.v. Memoria.

6 L. Sciascia, "Savinio", en Crucigrama, traducción de S. Mastrangelo México, Fondo de Cultura Económica, 1990, p. 207.

7 Ibídem, p. 210 su desprecio por la profundidad, por los escritores profundos (...) A partir de una condición de absoluta claridad, serenidad y libertad interior, de un luminoso conocimiento de uno mismo, incluso en lo que debería estar o se desearía que estuviese oscuro, ocurre el obvio fenómeno por el que la profundidad se transforma en superficialidad. No hay lugar profundo que la inteligencia no pueda volver superficial ${ }^{8}$.

Así pues, del mismo modo que él lo afirmaba del autor de Nuova Enciclopedia, también en el deleite sciasciano, "con su vagar por la cristalina, transparente superficialidad, la memoria, la Memoria, es la única y la gran musa, la que genera y contiene a todas las musas" ${ }^{\prime \prime}$. Como motivo inspirador de ésta e instrumento que pone en marcha su imaginación y su intelecto, Sciascia concede una gran importancia a las palabras. Según reconocía Sciascia en una entrevista, a él le inspiraba "la palabra: la simple palabra que sugiere, sugestiona, se abre como un abanico, despliega imágenes. Cuanto más envejezco, más atención presto a la palabra, a las palabras (...) Una palabra puede actuar en mí como elemento desencadenante de imaginación y de razón"10. De nuevo podemos establecer una correspondencia con la obra de Alberto Savinio, quien en la voz "Prosa" de la Nuova Enciclopedia elogia "a la palabra escrita, a la palabra silenciosa, al mensajero incoloro de la idea (...) y por eso deja libre juego a las ideas: unirse y oponerse, estimularse y enriquecerse alternativamente, ramificarse, formar ese río de ideas que, por doquier que pasa, echa abajo las ideas verticales y aisladas"11.

También en la escritura sciasciana opera constantemente ese juego de unión y oposición de ideas que se estimulan y enriquecen recíprocamente, ramificando y al mismo tiempo encauzando el relato. Al intervenir la rememoración literaria, esa operación está teñida por la afectividad del autor, que pone en órbita los

\footnotetext{
Ibídem, p. 211.

Ibídem, p. 212.

10 Cfr. C. Ambroise, "14 domande a Leonardo Sciascia", en L. Sciascia, Opere 1956-1971, C. Ambroise (ed.), Milano, Bompiani, [1987] 2001, pp. XXI-XXII.

11 Savinio, Nueva..., ob. cit., p. 340.
} 
escritores y obras que pertenecen a su constelación literaria ${ }^{12}$. Pero esa predilección apasionada por determinados escritores -y por eso, como apunta el narrador de Porte aperte (1987), “a veces, para algunas personas, el nombre de un escritor, el título de un libro pueden equivaler al de una patria"13 ${ }^{13}$ implica, paralelamente, la exclusión de otros. Así lo explicaba Sciascia cuando en aquella misma entrevista le pidieron su valoración sobre Dostoievski:

Es un grandísimo escritor, pero no lo amo. Ya sea pequeño o grande, un escritor no debe ser imparcial. Quien ama a Tolstoi no puede amar a Dostoievski, quien ama a Stendhal no puede amar a Proust, quien ama a Dante no puede amar a Petrarca. Decía Eugenio D'Ors: "Si La Fontaine es poeta, Víctor Hugo no lo es, y viceversa". Yo no llego a tanto: La Fontaine es poeta y también es poeta Víctor Hugo (por desgracia, según Gide, el más grande de los poetas franceses), pero no puedo amarles en igual medida: por desgracia, amo a Víctor Hugo ${ }^{14}$.

A su vez, cabría trasladar esa labor selectiva a la relación que se establece entre Leonardo Sciascia, en cuanto escritor, y sus lectores, y que le sitúa en la estela de una tradición que se remonta a Michel de Montaigne, continúa con Stendhal y más tarde con Savinio y que se manifiesta precisamente en la tarea de

elegir sus lectores, escogerlos como si en sus páginas hubiera un 'test' para una ardua, rigurosa, exclusiva selección: para admitirlos en esa conversación, para escogerlos -como dice Savinio- como compañeros ligeros, como arieles de un mundo en el que todo es, al mismo tiempo, simple y misterioso, evidente y secreto, 'superficial' y profundo ${ }^{15}$.

El tono íntimo y velado que adquiere con frecuencia la citación intertextual sciasciana, la recurrencia diacrónica de algunas de esas referencias a lo largo de sus obras (que sólo

12 Cfr. infra nota 47.

13 L. Sciascia, Puertas abiertas, traducción de R. Pochtar, Barcelona, Tusquets, 1988, p. 73 .

14 Ambroise, "14 domande...", ob. cit., pp. XVIII-XIX.

15 Sciascia, "Savinio o della conversazione", en Per un ritratto dello scrittore da giovane, Milano, Adelphi, 2000, p. 39. quien esté familiarizado con su universo poético está en condiciones de advertir) y la voluntad latente de dirigirse a un lector inteligente, entre otros elementos difícilmente ponderables, permiten aventurar que también Leonardo Sciascia era uno de esos escritores capaces de escoger sus propios lectores.

Pero el carácter diletante y divagante que adopta la escritura sciasciana no implica un abandono irracional u onírico, pues la memoria que la sustenta ha de ser "larga como la civilización, que no se confunde $-\mathrm{y}$ que es preciso evitar con sumo cuidado confundir- con los sueños"16. Al contrario, adquiere un carácter cívico, como labor desmistificante de las estructuras de poder, asociadas con la mentira y contra las que emplea con intención heurística las operaciones de lectura, escritura y reescritura.

\section{Leer, escribir y reescribir en busca de la verdad}

Aunque la escritura de Leonardo Sciascia tienda a alcanzar un tono divagante, que se alimenta de la memoria y de la citación intertextual, no por ello se constituye como una recreación erudita en el propio saber ni un refugio literario cerrado a la comprensión de la realidad. Por el contrario, el escritor busca hallar un sentido a dicha realidad a través de las coincidencias, refracciones y correspondencias que se establecen entre los hechos bajo la luz del propio bagaje literario. Pretende llevar a la superficie, por medio de la inteligencia, la profundidad de las cosas.

En esa tarea -y especialmente en el género del racconto-inchiesta ${ }^{17}$, que con tanta frecuencia cultivó Sciascia- adquieren una relevancia primordial, en cuanto instrumentos con valor

16 Ibídem, p. 213

17 Es un género que se podría traducir como "relato de investigación" y que fue inaugurado con la Storia della colonna infame de Alessandro Manzoni en 1842. De esta obra aprendió Sciascia a tomar como punto de partida algún hecho real, histórico, sobre el que se documentaba (a través de la prensa de la época, de actas judiciales, informes de la policía, diarios y testimonios de los protagonistas...) para luego reconstruirlo por medio de la narración y la inclusión en el relato de algunos de dichos documentos. 
heurístico, las operaciones de lectura, escritura y reescritura. En La scomparsa di Majorana (1975) el relato se construye sobre documentos de diversa índole (atestados policiales, correspondencia privada, testimonios, ensayos científicos) que exigen ser leídos con perspicacia y, en ocasiones, incluso reescritos para extraer de ellos todo aquello que pueda aproximar a la verdad sobre la vida y desaparición de Ettore Majorana ${ }^{18}$.

El narrador-Sciascia quiere "encontrar" al físico desaparecido y sabe que sólo podría hacerlo tomando como punto de partida esa escasa documentación ${ }^{19}$. Como explica en el capítulo noveno, intenta encontrarlo por medio de la escritura, "escribiendo estas páginas sobre su vida" ${ }^{20}$. Para escribir sobre su vida antes debe leerla y revivirla. Por eso, una exégesis correcta de los documentos requiere primero ponerlos en orden, "buscando en ellos un hilo conductor y una aclaración" ${ }^{21}$, detectando también las lagunas e imprecisiones de su contenido. Así lo explicaba Sciascia al inicio de "Mata Hari a Palermo", una de sus Cronachette (1984):

Los pequeños acontecimientos del pasado, esos que los cronistas relatan con imprecisión o reticencia y que los historiadores pasan por alto, a veces abren en mi labor cotidiana como un paréntesis, algo muy parecido a las vacaciones (...) La imprecisión o la reticencia con que se relatan los hechos es, naturalmente, la condición indispensable para que se desencadene el divertimento. Después viene el gusto por la indagación, por hacer encajar los datos o ponerlos en contradicción, hacer hipótesis, conseguir una verdad o establecer un misterio allí donde

18 Ettore Majorana fue un joven físico nacido en Catania en 1906 que desapareció misteriosamente en marzo de 1938. Había comunicado a un amigo su intención de suicidarse y su rastro se perdió poco después en una travesía en barco entre Nápoles y Palermo. Majorana trabajaba en el grupo de científicos que bajo la dirección de Enrico Fermi descubrió la escisión del átomo, hallazgo que precedió a la construcción de la bomba atómica. La hipótesis que defiende Sciascia en su libro es que, dado su carácter de genio como atestiguan quienes le conocieron, Majorana pudo intuir con bastante antelación que el fruto de sus investigaciones podría ser utilizado como un arma mortífera y, rechazando tal posibilidad por inmoral, decidió desaparecer, pero haciendo creer que se había suicidado.

19 Cfr. L. Sciascia, La desaparición de Majorana, traducción de J. M. Salmerón, Barcelona, Juventud, 1994, p. 13.

20 Ibídem, p. 56.

21 L. Sciascia, La Sicilia come metafora: intervista di Marcelle Padovani, Milano, Mondadori, 1979, p. 87. la falta de verdad no era un misterio o su presencia no era misteriosa ${ }^{22}$.

En último término, el éxito de la exégesis está condicionado por el grado de identificación que llegue a alcanzar el intérprete con el autor de los textos que ha de interpretar. En el caso de La scomparsa di Majorana, al igual que en L'affaire Moro, esto reviste una importancia aún mayor porque uno y otro están construidos en torno al drama vivido por una determinada persona (Ettore Majorana y Aldo Moro, respectivamente), del que dan constancia las últimas cartas que escribió cada uno de ellos ${ }^{23}$. En coherencia con su hermenéutica eminentemente literaria, Sciascia busca esa identificación con uno y otro según el modelo de un personaje de ficción, en concreto "el caballero Charles Auguste Dupin, el investigador de Poe, [que] consideraba precepto de toda investigación la capacidad de identificarse, de sumirse en el otro" ${ }^{24}$.

Para alcanzarla no basta con una observación atenta de los indicios, ni con un análisis cuidadoso de los documentos y testimonios. A la deducción lógica debe sumarse una inteligencia que simplifique las cosas sin caer en el reduccionismo, que las comprenda en su sencillez; de manera intuitiva y poética ${ }^{25}$. Al estudiar las últimas cartas enviadas por Majorana antes de su desaparición, la instancia narrativa de La scomparsa di Majorana descubre una frase que, pese a ser clara e inequívoca, había permanecido como oculta:

¿Qué quiere decir "no hay en ella ni un ápice de egoísmo" si no que la decisión procedía de muy distinto sentimiento e intención, de otro muy distinto dolor que el de la gastritis y de la jaqueca al cual algunos tienden a asociarla?

22 L. Sciascia, Mata-Hari en Palermo, traducción de R. Ruiz, Barcelona, Montesinos, 1986, p. 65.

23 En el caso de Aldo Moro, conviene recordar que era el presidente de la Democracia Cristiana italiana cuando fue secuestrado por las Brigadas Rojas el 16 marzo de 1978. Su cadáver apareció en el maletero de un coche en una calle romana el 9 de mayo, después de 55 días de cautiverio.

24 L. Sciascia, El caso Aldo Moro, traducción de A. Pentimalli, Barcelona, Destino, 1999, p. 42.

25 Cfr. E. Bacchereti, "Il "razionale mistero". Il poliziesco di Sciascia tra Poe, Gadda e Pirandello", en R. Cincotta (ed.), Da un paese indicibile, “Quaderni Leonardo Sciascia”, nº 4, Milano, La Vita Felice, 1999, p. 143. 
La frase está ahí, bien clara, sin equívocos; no obstante, hasta ahora, como en una especie de invisibilidad ${ }^{26}$.

Esta invisibilidad de una frase que, sin embargo, aparecía con toda claridad en el mensaje de Ettore Majorana es de nuevo una alusión intertextual a la obra de E. A. Poe. En concreto al cuento "La carta robada", donde el "exceso de evidencia" era lo que ocultaba el objeto que debía encontrar Dupin y que no estaba guardado en un sitio recóndito, sino dejado a la vista de todos, en un tarjetero ${ }^{27}$. Pero, más allá de esto, lo que revela desde el punto de vista hermenéutico el comentario del narrador de La scomparsa di Majorana es, como ha explicado Gaetano Compagnino, que

en el momento en que el lector cambia de lugar el centro de gravedad del texto, el propio texto se encuentra dislocado en una dimensión (de verdad) nueva y diversa (...) Dado que leer es "producción de sentido", leer equivale a escribir el otro texto: no un texto distinto, sino aquel que, inscrito en el primero (objeto de la lectura), la lectura -la relectura- "produce", saca fuera -a la "superficie" - escribiéndolo/reescribiéndolo como era, y, por eso mismo, también diferente ${ }^{28}$.

Sciascia toma como modelo de esta labor de reescritura a "Pierre Menard, autor del Quijote", que define en L'affaire Moro como "uno de los cuentos más extraordinarios que Borges haya escrito" ${ }^{29}$. El cuento narra la historia de ese ficticio autor francés, que escribió en el siglo XIX los capítulos noveno y trigésimo octavo de la primera parte del Quijote, y un fragmento del capítulo veintidós; iguales, en cada palabra y cada coma, a los escritos originalmente por Cervantes y, sin embargo (sostiene el narrador), sin ser una copia: "El texto de Cervantes y el de Menard son verbalmente idénticos, pero el segundo es casi infinitamente más rico"30. Así

\footnotetext{
26 Sciascia, La desaparición..., ob. cit., p. 52.

27 Cfr. E. A. Poe, Cuentos, vol. 1, traducción y prólogo de J. Cortázar, Madrid, Alianza, 1994, pp. 514-534.

28 G. Compagnino, Leonardo Sciascia nella terra dei letterati, Acireale, Bonanno Editore, 1994, p. 125.

29 Sciascia, El caso..., ob. cit., p. 23.

30 J. L. Borges, Ficciones, Barcelona, Planeta-De Agostini, 1985, p. 56.
}

pues, por medio de la lectura y de la reescritura, un texto, aun siendo el mismo en su literalidad, puede adquirir diferentes significados dentro de un nuevo contexto.

Sin duda esta cuestión de la recepción literaria es compleja y requeriría un mayor desarrollo, pero no nos parece oportuno realizarlo en estas páginas ${ }^{31}$. Baste con añadir, por lo que respecta a Sciascia, que éste incluso confería a la obra de escritores como Stendhal o Savinio "una posibilidad inagotable, abierta a una inagotable apropiación, que se renueva y multiplica a cada relectura" ${ }^{\prime 32}$.

En más de una ocasión, Sciascia puso de manifiesto la importancia que todo ese proceso vinculado a la lectura, escritura y reescritura tenía en la conformación de su universo poético: "Ya no es posible escribir: se reescribe. $Y$ en este obrar -más o menos conscientemente- hay desde un reescribir que atañe al escribir (Borges) hasta un torpe y a veces indigno reescribir. Por así decirlo, yo he hecho del reescribir mi poética: un reescribir consciente, abierto, que no es torpe y en absoluto innoble" ${ }^{\prime 33}$. Desde ahí, por tanto, cabe explicar también la recurrente intertextualidad empleada por Sciascia, que convierte sus páginas en un diálogo continuo con la tradición literaria. Al mismo tiempo en ellas está arraigada la conciencia moral de que la escritura tiene una capacidad performativa, de que "todo está vinculado al problema de la justicia, en el que se entremezclan los problemas de la libertad, de la dignidad humana, del respeto entre los hombres. Es un problema que se asoma a la escritura, que en la escritura encuentra redención o condena" ${ }^{34}$.

Por eso, en La scomparsa di Majorana afirma que es necesario releer las últimas cartas escri-

31 Sobre este asunto cfr., entre otros, W. Iser, The Act of Reading: a Theory of Aesthetic response, Baltimore, Johns Hopkins University Press, 1980; H. R. Jauss, Experiencia estética y hermenéutica literaria, traducción de J. Siles y E. Fernández-Palacios, Madrid, Taurus, 1986; R. Warning (ed.), Estética de la recepción, traducción de R. Sánchez, Madrid, A. Machado Libros, 1989; L. A. Acosta, El lector y la obra: teoría de la recepción literaria, Madrid, Gredos, 1989.

32 Sciascia, "Savinio...", ob. cit., p. 211.

33 Ambroise, "14 domande...", ob. cit., p. XVI.

34 Ibídem, ob. cit., p. XXI. 
tas por Ettore Majorana antes de desaparecer, aunque ya fueron publicadas y son de dominio público $^{35}$. Y de la misma manera sucede con los demás documentos que el escritor integra en todos sus racconti-inchiesta porque, en definitiva, como afirma Claude Ambroise en su ensayo "Verità e scrittura":

Sciascia cree en la posibilidad de alcanzar, a través de las trazas escritas dejadas en los archivos, la verdad de los hechos pasados. Por lo menos, es posible descubrir que la verdad ha sido escondida, que ha existido, que la impostura de los papeles encierra una verdad. Las cosas pueden no haber ocurrido como el redactor del documento intentaría hacernos creer pero, al menos como ausencia, la verdad es intuible. La verdad está en la relación entre el texto y quien lo ha escrito. De ahí también la importancia decisiva de la reescritura, del trabajo propiamente literario operado por Sciascia sobre el material encontrado ${ }^{36}$.

Si proyectamos esta consideración sobre la producción literaria sciasciana de ficción policiaca, podemos reconocer que también las operaciones de lectura, escritura y reescritura son parte consustancial de los gialli ${ }^{37}$ del escritor de Racalmuto, tanto en el plano metadiscursivo como en la propia dinámica argumental de los hechos narrados.

\section{El escritor como un detective policial}

Desde la perspectiva sciasciana el discurso detectivesco es el que mejor se adecua a su voluntad de descifrar la realidad. Por ello, en mayor o menor medida, ya sean gialli, racconti-inchiesta o ensayos, casi todas sus obras comparten una estructura esencialmente policiaca. Como explica el autor de Le parrocchie di Regalpetra:

\footnotetext{
35 Sciascia, La desaparición..., ob. cit., p. 52.

36 C. Ambroise, "Verità e scrittura", ensayo introductorio a Sciascia, Opere 1956-1971..., ob. cit., p. XLIV.

37 En Italia, el género de novela policiaca se conoce por el color de la portada (giallo, es decir, amarillo) de la primera colección editada por Mondadori en 1929, de igual manera que en Francia -y por extensión en muchos países- se llama noir (negro) en alusión a la colección Série Noire de novela policiaca que Gallimard comenzó en 1945.
}

El escritor desvela la verdad descifrando la realidad y elevándola a la superficie, en cierto sentido simplificándola, también haciéndola más oscura, como la realidad a menudo es (...) Existe, no obstante, una diferencia entre esta oscuridad y la de la ignorancia: ya no se trata de la oscuridad de lo inexpresado, de lo informe; sino, al contrario, de lo expresado y de lo formulado. Por eso utilizo con frecuencia el "discurso" de la novela policiaca, esta forma de relato que tiende a la verdad y a la denuncia del culpable, si bien no siempre se llega a encontrar al culpable ${ }^{38}$.

Efectivamente, en los gialli sciascianos se le priva al lector de la restitución del orden que ha roto el delito y, por tanto, del final feliz habitual. Bien no se resuelve el misterio (no queda claro en última instancia quién es el culpable y todo queda en la sombra de la duda), bien se descubre la verdad, pero no triunfa debido a la muerte del investigador (Rogas en Il contesto, Laurana en A ciascuno il suo, el Vice en Il cavaliere e la morte) o a su aislamiento en un sistema político-judicial en connivencia con la mafia y que obstaculiza su investigación (el caso de Bellodi en Il giorno della civetta y de Lagandara en Una storia semplice).

Con palabras de Schulz-Buschhaus, la narración no concluye "con la imagen ficticia de un orden reestablecido ni en el plano de la moral ni del conocimiento. El lector aprende, al contrario, a conocer la única claridad posible: incertidumbre, interrogantes y presupuestos para la reflexión" ${ }^{39}$. La razón de que se le prive al lector del happy end habitual se debe, como apunta Ambroise, al hecho de que

la certeza de que el criminal será desenmascarado y castigado es una impostura asumida como postulado de la novela policiaca clásica, pero no puede formar parte del concepto sciasciano de "escritura-verdad". De hecho, en los libros de Sciascia no es el policía quien proclama artificialmente la solución de un enigma, sino el propio autor el que expresa y

38 Sciascia, La Sicilia..., ob. cit., p. 87.

39 U. Schulz-Buschhaus, "Gli inquietanti romanzi polizieschi di Sciascia", en A. Motta (ed.), Il sereno pessimista. Omaggio a Leonardo Sciascia, Manduria, Lacaita, 1991, p. 165. 
denuncia los mecanismos de la sociedad en la que vive (...) La eliminación física del policía es significativa de una sociedad, de una especie de despenalización del delito, puesto que es la criminalización del Estado la que genera este tipo de homicidio ${ }^{40}$.

No obstante, más allá de la naturaleza trágica de lo que el escritor a menudo reproduce en sus páginas, anida en Sciascia la convicción de que su oficio es una potenciación del placer de vivir; de que por muy amargas, dolorosas y angustiosas que sean las cosas sobre las que uno escribe, el escribirlas es ya siempre un motivo de alegría, un "estado de gracia"41. Y en la misma medida en que el autor disfrute con la escritura, así será para el lector su recepción ${ }^{42}$.

Esta deleitación literaria está vinculada con la vivencia de la verdad, que es el resultado de un recorrido hermenéutico por el cual el escritor descifra la realidad leyéndola y escribiéndola, extrayendo lo sencillo de lo complejo. La literatura rescata a la realidad de la complejidad y de la profundidad (la lleva con la inteligencia a la superficie), pero no necesariamente de la oscuridad. Restituye el verdadero sentido de los hechos -aunque siga siendo una verdad misteriosa- porque los libera de la retórica y la mistificación que provienen del poder y del Estado, vistos por Sciascia como una máquina productora de mentira ${ }^{43}$. A este respecto, el escritor siciliano piensa que la historiografía

40 C. Ambroise, La letteratura come strumento di verità?, en S. Landi (ed.), Leonardo Sciascia. Cinema e letteratura, Pordenone, Cinemazero, 1995. Ya lo argumentaba así el propio Sciascia en 1966, en boca del narrador de A ciascuno il suo: "Que un crimen se ofrezca al investigador como un cuadro cuyos elementos materiales y, por así decirlo, estilísticos permitan, debidamente descubiertos y analizados, una inculpación segura, es corolario de todas esas novelas policiacas de las que bebe buena parte de la humanidad. La realidad, sin embargo, es muy distinta: el grado de impunidad y error es alto no porque sea bajo el coeficiente intelectual del investigador (o no solamente o no siempre por eso), sino porque los elementos que un crimen presenta suelen ser absolutamente insuficientes", en L. Sciascia, A cada cual, lo suyo, traducción de J. M. Salmerón, Barcelona, Tusquets, 2009, p. 63.

41 Cfr. L. Sciascia, La bruja y el capitán, traducción de J. R. Monreal, Barcelona, Tusquets, 1989, p. 108.

42 "Cada año, aquí en el campo, para mí es un descanso y un entretenimiento escribir un libro, un pequeño libro, cualquiera que sea el tema, la materia. El descanso y el entretenimiento de la escritura, el placer de hacer un texto (placer que es, para un autor, la única manera de calibrar lo que será para el lector y para el crítico -me refiero al crítico capaz de no perder la condición de lector-el placer del texto)", en Sciascia, Negro..., ob. cit., p. 294.

43 Cfr. L. Sciascia, La palma va a nord, Milano, Grammalibri, 1982, p. 155. tampoco está libre de dicha mentira, pues puede ser empleada como instrumento de justificación ideológica. La literatura es necesaria para la comprensión del pasado y por eso recurre a ella como escritor, de ahí su opción por el género del racconto-inchiesta, y también como lector:

Descubro en la literatura aquello que no logro descubrir en los analistas más elucubrantes, esos que querrían ofrecer explicaciones y soluciones a todos los problemas. Sí, la Historia miente y sus mentiras envuelven de un mismo polvo todas las teorías que nacen de la Historia (...) Se descubre una verdad histórica, no ya en un texto de historia, sino en las páginas de una novela; no en un docto análisis, sino gracias a una descripción novelada ${ }^{44}$.

Una muestra de la función restitutiva y a la vez profética de la literatura sería el secuestro y ejecución en 1978 del líder democristiano Aldo Moro, en tanto que todo el proceso parecía según Sciascia una proyección real de lo que él ya había escrito anteriormente en ficciones como $\mathrm{Il}$ contesto o Todo modo. En definitiva, como afirmó luego en L'affaire Moro, "abandonada la verdad a la literatura, cuando apareció aquélla, dura y trágica, en el espacio cotidiano y ya no fue posible ignorarla o tergiversarla, pareció generada por la literatura" 45 .

Por todo lo anterior, Sciascia llega a la convicción de que la literatura es el espacio donde la verdad puede alcanzar su plenitud, abandonando así una concepción de la escritura como engaño y falsificación:

En mi casa siempre se ha respirado un infinito respeto por las cosas de la escritura, un respeto y un miedo típicos del mundo campesino. Para el campesino, ¿la escritura no es quizá engaño, impostura y falsificación? (...) De la "escrituraengaño", como era para el campesino y como era para mí mismo, he llegado a la "escrituraverdad" y me he convencido de que, si la verdad necesariamente ofrece muchas caras, la única forma posible de verdad es aquella del arte ${ }^{46}$.

\footnotetext{
44 Sciascia, La Sicilia..., ob. cit., p. 82.

45 Sciascia, El caso..., ob. cit., p. 28.
}

46 Sciascia, La Sicilia..., ob. cit., p. 87. 
La imagen usada por el escritor para explicarlo es la de un "sistema solar": la literatura como un firmamento de escritores y libros que "de forma variada, alternativa e imprevisible resplandecen y se eclipsan, de nuevo resplandecen y se eclipsan -y así sucesivamente- a la luz de la verdad"47. No es un reflejo de la realidad, sino un repertorio de la memoria universal articulado como un sistema de arquetipos a la luz del cual la realidad adquiere su sentido, y no al contrario; en el que la realidad acaba siendo una copia más oscura y degradada que sus arquetipos literarios ${ }^{48}$.

Il cavaliere e la morte es un caso paradigmático de cómo funciona desde la perspectiva sciasciana dicho sistema. El protagonista, un subcomisario de policía, se constituye en el relato como alter ego del escritor. Ambos comparten una situación vital marcada por una grave enfermedad; lo cual, unido a otros rasgos de la caracterización del personaje que evidencian claras connotaciones autobiográficas ${ }^{49}$, nos lleva a concluir que, a través del protagonista de esta novela, Leonardo Sciascia puso en órbita, verdaderamente por última vez, su "sistema solar" literario. Sirviéndose del género policiaco - pero privando al lector de la restitución final del orden, impropia de su noción de "escritura-verdad" - dio su última palabra sobre la relación entre la persona y el poder, sobre la memoria, sobre Sicilia, sobre la vida y la muerte; al mismo tiempo que retrataba, desde la óptica de su extensa y vasta formación cultural, sus preferencias literarias, los escritores y libros que durante toda una vida había leído y releído para intentar vivir y hacer vivir la verdad.

Un ideal que de modo sintético ya había señalado en 1958, en boca del protagonista de su cuento titulado "Il Quarantotto": "Escribir me parece un modo de hallar consuelo y descanso, una manera de reencontrarme por fin, al mar-

47 Sciascia, Negro..., ob. cit., p. 298.

48 Cfr. M. Onofri, Il sospetto della realtà. Saggi e paesaggi italiani novecenteschi, Cava de' Tirreni, Avagliano, 2004, p. 83.

49 El Vice (como se llama el personaje, simplemente en virtud de su empleo) comparte con Leonardo Sciascia las mismas preferencias literarias, la afición por el coleccionismo artístico, la visión irónica de la realidad o la adicción al tabaco. gen de las contradicciones de la vida, ante un destino cierto" ${ }^{\prime 50}$.

\section{Bibliografía}

1. Acosta, L. A., El lector y la obra: teoría de la recepción literaria, Madrid, Gredos, 1989.

2. Borges, J. L., Ficciones, Barcelona, PlanetaDe Agostini, 1985.

3. Cincotta, R. (ed.), Da un paese indicibile, "Quaderni Leonardo Sciascia", no 4, Milano, La Vita Felice, 1999.

4. Collura, M., Sciascia. El maestro de Regalpetra, traducción de M. J. Palomera, Madrid, Alfaguara, 2001.

5. Compagnino, G., Leonardo Sciascia nella terra dei letterati, Acireale, Bonanno Editore, 1994.

6. Iser, W., The Act of Reading: a Theory of Aesthetic Response, Baltimore, Johns Hopkins University Press, 1980.

7. Jauss, H. R., Experiencia estética y hermenéutica literaria, traducción de J. Siles y E. Fernández-Palacios, Madrid, Taurus, 1986.

8. Landi, S. (ed.), Leonardo Sciascia. Cinema e letteratura, Pordenone, Cinemazero, 1995.

9. Motta, A. (ed.), Il sereno pessimista. Omaggio a Leonardo Sciascia, Manduria, Lacaita, 1991.

10. Onofri, M., Il sospetto della realtà. Saggi e paesaggi italiani novecenteschi, Cava de' Tirreni, Avagliano, 2004.

11. Poe, E. A., Cuentos, vol. 1, traducción y prólogo de J. Cortázar, Madrid, Alianza, 1994.

12. Ricorda, R., Pagine vissute. Studi di letteratura italiana del Novecento, Napoli, Esi, 1995.

50 L. Sciascia, "Il Quarantotto", en Los tíos de Sicilia, traducción de A. Citraro, Barcelona, Tusquets, 2001, p. 119. 
13. Savinio, A., Nueva enciclopedia, traducción de J. Pardo, Barcelona, Seix Barral, 1983.

14. Sciascia, L., La Sicilia come metafora: intervista di Marcelle Padovani, Milano, Mondadori, 1979.

15. Sciascia, L., La palma va a nord, Milano, Grammalibri, 1982.

16. Sciascia, L., Mata-Harien Palermo, traducción de R. Ruiz, Barcelona, Montesinos, 1986.

17. Sciascia, L., Opere 1956-1971, C. Ambroise (ed.), Milano, Bompiani, [1987] 2001. El volumen incluye la entrevista de C. Ambroise, "14 domande a Leonardo Sciascia" y su ensayo introductorio "Verità e scrittura".

18. Sciascia, L., Puertas abiertas, traducción de R. Pochtar, Barcelona, Tusquets, 1988.

19. Sciascia, L., La bruja y el capitán, traducción de J. R. Monreal, Barcelona, Tusquets, 1989,

20. Sciascia, L., El caballero y la muerte, traducción de R. Pochtar, Barcelona, Tusquets, 1989.
21. Sciascia, L., "Savinio", en Crucigrama, traducción de S. Mastrangelo México, Fondo de Cultura Económica, 1990.

22. Sciascia, L., La desaparición de Majorana, traducción de J. M. Salmerón, Barcelona, Juventud, 1994.

23. Sciascia, L., El caso Aldo Moro, traducción de A. Pentimalli, Barcelona, Destino, 1999.

24. Sciascia, L., "Savinio o della conversazione", en Per un ritratto dello scrittore da giovane, Milano, Adelphi, 2000.

25. Sciascia, L., "Il Quarantotto", en Los tíos de Sicilia, traducción de A. Citraro, Barcelona, Tusquets, 2001.

26. Sciascia, L., Negro sobre negro, traducción de C. Palma, Barcelona, Global Rhythm Press, 2007.

27. Sciascia, L., A cada cual, lo suyo, traducción de J. M. Salmerón, Barcelona, Tusquets, 2009.

28. Warning, R. (ed.), Estética de la recepción, traducción de R. Sánchez, Madrid, A. Machado Libros, 1989. 